\title{
A Conversation Between Johannes Czernin and Hong Wu
}

\author{
Hong $\mathrm{Wu}, \mathrm{MD}, \mathrm{PhD}$ and Johannes Czernin \\ School of Medicine, UCLA, Los Angeles, California
}

$\mathbf{J}$ ohannes Czernin, MD, talked with Hong $\mathrm{Wu}, \mathrm{MD}, \mathrm{PhD}$, professor and dean of the School of Life Sciences and a senior investigator of the Peking-Tsinghua Center for Life Sciences at Peking University (Beijing, China). Dr. Wu received her medical degree from Beijing Medical College in 1983 and a $\mathrm{PhD}$ from Harvard Medical School (Boston, MA) in 1991. After postdoctoral training as a Damon Runyon-Walter Winchell postdoctoral fellow at the Whitehead Institute for Biomedical Research at the Massachusetts Institute of Technology (Cambridge, MA), she joined the University of California at Los Angeles (UCLA) as an assistant professor in 1996 and was appointed a tenured full professor in 2005. She was the David Geffen Professor and the director of the Institute for Molecular Medicine at UCLA before returning to Peking University in 2013. Among her numerous honors are the Pew Scholar Award and the Howard Hughes Assistant Investigator Award. She is a fellow of the American Association for the Advancement of Science and an associate member of the European Molecular Biology Organization. A major research focus of the Wu laboratory is the molecular mechanism of PTEN-controlled tumorigenesis and signaling pathways. By generating tissue-specific PTEN-deficient animal models, her lab was the first to demonstrate the role of the PTEN tumor suppressor in regulating stem cell G0-G1 cell cycle entry, self-renewal, proliferation, survival, and formation of cancer stem cells. These models have been used for investigating crosstalk between the PI3K and other signaling pathways in tumorigenesis and serve as valuable tools for new drug development for human cancers.

Dr. Czernin: I want to start out with a brief summary of your career and personal history. You had a very complex and often difficult journey from China to the United States and back. Can you tell us a little bit about your life experience?

Dr. Wu: I was born in Beijing, China, and grew up in an intellectual family. I attended elementary school for only 2 y before the Chinese Cultural Revolution started. I had no formal and continuous schooling for several years before being sent to the countryside to be "reeducated," a term used during that time. I did farm work and took care of the farmers as a "barefoot doctor," the term for individuals who received minimal basic medical and paramedical training and worked in rural villages in China. I learned how to make traditional Chinese medicine and did my first biology-related experiments by selecting the best seeds from the wheat. When the Cultural Revolution ended, everything changed. Chinese universities reopened after being closed for $10 \mathrm{y}$. I had a life-changing opportunity to take the national entrance exam and entered medical school in 1978.

COPYRIGHT @ 2021 by the Society of Nuclear Medicine and Molecular Imaging. DOI: 10.2967/jnumed.121.262007
Dr. Czernin: Was that very competitive?

Dr. Wu: It was extremely competitive, because after $10 \mathrm{y}$ of closed schools so many students had dreamed about entering universities. For factory workers or farmers like me, it was very difficult to compete with students freshly graduated from high school. I had to work hard to catch up. Initially, I applied to the Department of Chemistry of Peking University, because I had really liked chemistry during my

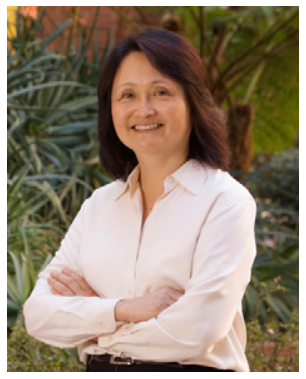
brief stint in middle school. Then, people in my village asked "Why don't you want to study medicine? This way, when you become a doctor, we can go to the city and visit you in the hospital." Remembering how rewarded I felt when taking care of farmers as a young "doctor" under the most deprived conditions, I decided to change my application. My first choice was Beijing Medical College, now Peking University Health Science Center.

Dr. Czernin: Was this a mixed education between Western and traditional Chinese medicine, or was it only Western medicine?

Dr. Wu: The majority of the curriculum was Western medicine-based. But in our senior year, we had a semester of traditional Chinese medicine. We learned about herbs, acupuncture, and how to test and interpret pulses-all very basic information.

Dr. Czernin: When you graduated from medical school, what happened next? Did you work as a physician afterward?

Dr. Wu: I didn't. There were several major changes in China after I entered medical school in 1978. China not only reopened its universities but also opened its doors to the Western world. Deng Xiaoping, the chief architect of China's reform and globalization, developed a national strategic plan. As part of this plan, China wanted to send its students to the United States, Europe, and Japan for education. This came after the realization that science and technology were critically important for national growth, and the best way to reach these goals was to send bright students abroad.

There were several programs being established. The first was the China-U.S. Physics Examination and Application program (1979-1989), created by the Chinese-American physicist and Nobel laureate Tsung-Dao Lee, PhD. I belonged to the China-U.S. Biochemistry Examination and Application (CUSBEA) program (1982-1989), established by the Chinese-American biochemist Ray $\mathrm{Wu}, \mathrm{PhD}$, from Cornell University (Ithaca, NY), and run by Peking University.

Dr. Czernin: They went to China to bring the best students to the United States?

Dr. Wu: Correct. Each program first approached the top U.S. universities for their willingness to join the program and accept 
Chinese students. Then examination committees were established. In my case, I first took the national graduate student entry exam in Chinese, then was recommended to take the CUSBEA exam in English. The top students were then interviewed by the examination committee, made up of professors from the U.S. universities within the program. The committee made the decisions for admission and also wrote letters of recommendation for each Chinese student.

I was very lucky to be admitted to Harvard Medical School in 1984 as a graduate student. After 2 y, I chose a lab in the Whitehead Institute at Massachusetts Institute of Technology. My thesis advisor was Rudolf Jaenisch, MD, a pioneer in leveraging molecular genetic approaches to study human diseases. My training in Rudolf's lab exposed me not only to various molecular genetic approaches but also to the process of asking important and mechanistic questions in biology and medicine.

I received my $\mathrm{PhD}$ in biologic chemistry and molecular pharmacology from Harvard Medical School in 1991. In 1990, before graduation, my husband and I had been thinking of returning to China and visited several places in Beijing. But research opportunities in China were very limited at the time, and many senior faculty advised us to continue our training as postdoctoral scholars in the United States. Therefore, I joined the lab of Harvey Lodish, $\mathrm{PhD}$, at the Whitehead Institute to study the in vivo function of erythropoietin and the signaling pathway driven by the erythropoietin receptor. Later my husband and I applied for faculty positions, and we were recruited to UCLA in 1996. of the School of Life Sciences and she wanted to recommend me for the position.

The major turning points in my life were all related to Peking University. The first was in 1978 when I had the opportunity to take a national exam and enter Beijing Medical College, now the Health Science Center of Peking University. The second was in 1983 when I took the CUSBEA exam organized by Peking University, which paved the way for my training and research career in the United States. Peking University is not only my alma mater but also that of my father and grandfather. Although I have tremendous respect for this great university, I was hesitant to make such a big decision. After many discussions with my husband and family, my close friends, and colleagues, I felt an obligation to contribute to research and education in China. So, I applied and was selected by the recruitment committee: the third turning point in my life. After nearly $30 \mathrm{y}$ in the United States, I now have the honor and privilege to serve the faculty and students at Peking University and the opportunity to be close to my parents during the last stage of their lives.

Dr. Czernin: You know the structure at major universities in the United States very well. There is academic freedom and independence. Yet there is also a lot of centralized decision making to meet institutional goals, recruitments, budgets, etc. How does that work in Beijing? How much autonomy do you have in your decision processes?

Dr. Wu: These are all really important questions. Peking University was the first public university founded in the Qing Dynasty and is the leading institute in modern Chinese education. The

\section{"If scientific discoveries and innovations are the engines of a society, then the best minds and talents are the fuel that powers that engine to drive a society forward. How can a society move forward if we deprive it of the talent that has kept it going?"}

Before I left Whitehead, I asked my mentors and other senior faculty for advice. A unanimous recommendation was to "do something different." In 1997, after I had just set up my own lab at UCLA, 3 labs simultaneously identified a putative tumorsuppressor gene called PTEN. As I was always interested in the molecular mechanisms of cancer, I immediately shifted my lab's focus to PTEN.

Dr. Czernin: You were highly successful at UCLA. You received millions of dollars in grant support. In between, you also became a Howard Hughes professor. You were actually humming along. So, why did you change your life again and return to China in 2013?

Dr. Wu: I actually had no intention to change my life and leave UCLA. I really enjoyed my time in the United States, the mentorship, and the whole creative research environment at UCLA. I also had gone through some very difficult times. In 2001, my husband had 2 bad strokes. Although he survived, his language center was destroyed. It was very difficult for him to function as a faculty member. In the following $12 \mathrm{y}$, I was very busy, taking care of our 2 little children, our 2 labs, and, at the same time, taking leadership roles at UCLA. Our labs and children were doing well, and our second child would go to university in the summer of 2013. I thought that finally I could relax and enjoy my own life. But, in the summer of 2012, one of my closest friends called and told me that Peking University had opened an international search for the dean university council and the president govern the university. Then there are divisions, including science, information, engineering, humanities, and the social sciences, as well as the Health Science Center. In terms of autonomy, as the dean, I have the responsibility to select the associate deans and build a strong, focused, and collegial leadership. This obviously needs to be approved by the university. I also negotiate a 5-y budget with the university and have the autonomy to decide on how to use that budget with the leadership under university budget regulations. Another one of my major responsibilities has been recruiting new faculty and shaping the future research direction of our school.

Dr. Czernin: All this power in your hands could create a problem for departments that then cannot decide their own programmatic direction. Is it always a collaborative effort?

Dr. Wu: It is always a collaborative effort. I consult faculty and build consensus for major decisions-a process very similar to the University of California system.

Dr. Czernin: You have the 5-y fund, which is nice to start with, but is there something like a Chinese National Institutes of Health? If so, how much of the budget that you have for your research programs comes from support that is not part of the 5-y plan?

Dr. Wu: The dean's fund is only for recruiting and supporting the school's research platform, programs, and daily operations. It is obviously not sufficient for some of the new initiatives we intend to launch, so I devote a large amount of my time and effort to 
fundraising, similar to deans in the United States. Faculty members need to apply for research funding through national agencies, such as the Ministry of Science and Technology and National Science Foundation, to support their own lab operations.

Dr. Czernin: Is it as tough to get grants as it is in the United States?

Dr. Wu: It is much better. In comparison to the single-digit success rate in the United States, we have double-digit success rates for national funding agencies. Funding provided by the Ministry of Science and Technology can support program projects comparable to National Institutes of Health Specialized Programs of Research Excellence or P01 grants. The Chinese National Science Foundation is similar to the National Science Foundation in the United States and funds individual projects. Then there is also local funding. Different provincial governments, even different cities, offer funding for science and technology development.

Dr. Czernin: Does your tenured faculty have a mandatory retirement age?

Dr. Wu: Tenure system is actually new in China. Peking University started to implement a tenure review system in 2014 that is quite similar to that in the University of California system. Before the tenure review system, almost everyone who worked in the university held a permanent position. The retirement age for full professors is 65 .

Dr. Czernin: Many academic U.S. institutions have established close relationships with industry. How are such relationships managed in China? Was there a lot of pushback initially from the old faculty that this is not something that should be done, or was it easy?

Dr. Wu: I collaborated with many pharmaceutical companies when I was in the United States and understand how important these relationships are for translating basic research from bench to bedside. We set up the Peking University-Bayer Health Sciences strategic collaboration in 2014 and have now built several strong industry-academia relationships, including the Peking University-Boehringer Ingelheim collaboration established in 2017. I did not get any pushback from our faculty, as I always communicate with my colleagues about my intentions and why I find these collaborations important. We also established a close collaboration with local government, similar to the Massachusetts Life Sciences Initiative, to create an innovation ecosystem.

Dr. Czernin: You mentioned that at times you missed the translational research opportunities and collaborations that you had in the United States because the clinical and preclinical sciences were better integrated. Is this gap still difficult to bridge?

Dr. Wu: I think it is getting better and better, but we still have a long way to go. Although China has huge possibilities for clinical research with its large and diverse population, the links between clinical and basic research still need to be forged and strengthened. One major area that needs improvement is credit assignment. As an example, imagine a collaboration with a physician in which he or she provides cancer tissue samples from patients. The physician did the initial work by recruiting the patients, obtaining the samples, and providing the treatment. From there, I do the heavy lifting by performing analyses on the patient samples. How do I distribute the credit? Who should be first author, and who should be last author? Authorship is important because of the way in which we evaluate our faculty and physician scientists. However, overall, there has been a push from the central government to integrate clinical and basic research as it has become clear that translational work will help drive science forward. I think these efforts are bearing fruit as the quality and number of publications from Chinese researchers is improving year after year.

Dr. Czernin: You are working on collaborative opportunities across departments. What about international collaborations? Do you see progress in the collaboration between Chinese and American institutions? Here is a quote from Joanna Fowler, PhD, one of the key developers of ${ }^{18} F-F D G$ : "I am worried about the recent discrimination against Chinese-American scientists. I worry a lot about this. This transcends many of the basic problems of tracer development. What will the workforce of the future be if we exclude scientists from other countries or if we make them feel unwelcome?"

Dr. Wu: I very much agree with Joanna. Training in the United States has shaped me as a scientist and as an educator, and I am forever grateful for my mentors, close friends, and colleagues, as well as the institutes and foundations that supported me. I worry about recent discrimination against immigrants and, more specifically, Chinese-American scientists. I am deeply concerned about the well-being of our children, close friends, colleagues, and the future of science. My postdoc advisor, Harvey Lodish, recently sent me 2 articles he wrote about the U.S. economy, science, and immigrants, with a teaser: " 1 of 3 of our top scientists appointed to the U.S. National Academy of Sciences was foreign-born." If scientific discoveries and innovations are the engines of a society, then the best minds and talents are the fuel that powers that engine to drive a society forward. How can a society move forward if we deprive it of the talent that has kept it going?

Dr. Czernin: Has the situation changed recently?

Dr. Wu: Situations have definitely changed, both because of systematic discrimination and more acutely from the pandemic. At the faculty level, many professors we might invite for meetings and collaborations now are concerned about having scientific collaborations with Chinese scientists. For Chinese students applying for graduate school or postdoctoral programs, the road is full of uncertainty. Many have been considering staying in China or seeking experience in Europe instead of applying for programs in the United States.

Dr. Czernin: My last question is about COVID-19. As the pandemic is not under control in the United States, we still experience limitations for our preclinical work with limits in lab occupancy. Is that completely over at your university, are you fully staffed again, or is it also still limited?

Dr. Wu: Yes, we are fully staffed now. All students have returned to campus, and we are allowed to hold in-person classes, meetings, and seminars. We still wear face masks whenever we go out in public or in crowded environments.

Dr. Czernin: What about testing?

Dr. Wu: It is really, really important. During the pandemic, we've managed to maintain our basic research needs, such as animal husbandry, and critical research projects related to the pandemic through an aggressive testing and quarantine program.

Dr. Czernin: I just realized that you talked about COVID-19 in the past tense, which is quite remarkable, because for us, it's absolutely not in the past. It's very much in the present throughout most of the country. Let's hope that with reason and discipline and vaccines, things will slowly return to normal in 2021. Thank you, Hong, for taking the time to tell our readers your life story and your insights into academia in China. 